\title{
Increasing expression of hypoxia-inducible proteins in the Barrett's metaplasia-dysplasia-adenocarcinoma sequence
}

\author{
EA Griffiths ',2, SA Pritchard ${ }^{3}$, SM McGrath ${ }^{3}$, HR Valentine', PM Price', IM Welch ${ }^{2}$ and CML West*, \\ 'Academic Radiation Oncology, Division of Cancer Studies, Christie Hospital, The University of Manchester, Wilmslow Road, Withington, Manchester M20 \\ 4BX, UK; ${ }^{2}$ Department of Gastrointestinal Surgery, University Hospitals NHS Trust, South Manchester, Manchester M23 9LT, UK; ${ }^{3}$ Department of \\ Histopathology, University Hospitals NHS Trust, South Manchester, Manchester M23 9LT, UK
}

\begin{abstract}
Hypoxia-associated markers are involved in the progression of several malignancies, but are relatively unstudied in Barrett's carcinogenesis. Our aim was to assess the immunohistochemical expression of hypoxia-inducible factor (HIF)-I $\alpha$, HIF- $2 \alpha$, erythropoietin (Epo), Epo receptor (Epo-R), Glut-I and vascular endothelial growth factor (VEGF) along with Ki67/MIB-I in the Barrett's metaplasia-dysplasia-adenocarcinoma sequence. Endoscopic biopsies of normal squamous epithelium (NSE) ( $n=20$ ), columnar-lined oesophagus (CLO) $(n=15)$, CLO with intestinal metaplasia $(n=20)$, dysplasia $(n=17)$ and Barrett's type adenocarcinoma $(n=20)$ were obtained. Immunohistochemistry was performed on the paraffin-embedded tissue. A score was calculated for each marker (range 0-300) by multiplying intensity (none 0, weak I, moderate 2, strong 3) by percentage of expression (range 0 - I00). Significant increases in the expression of HIF- $2 \alpha(P=0.0 \mathrm{I} 4)$, VEGF $(P<0.000 \mathrm{I})$, Epo-R $(P<0.000 \mathrm{I})$ and Ki67 $(P<0.000 I)$ were found as tissue progressed from NSE to adenocarcinoma. HIF- $2 \alpha$ was expressed late in the sequence and was only seen in dysplasia and adenocarcinoma. High HIF- $2 \alpha$ expression was seen in 12 out of 20 Barrett's type adenocarcinoma. The late expression of HIF-2 $\alpha$ in the Barrett's carcinogenesis sequence and its high expression in adenocarcinoma suggest that it is worth further investigation as a marker of disease progression and therapeutic target.
\end{abstract}

British Journal of Cancer (2007) 96, 1377- 1383. doi: I0.1038/sj.bjc.6603744 www.bjcancer.com

Published online 17 April 2007

(c) 2007 Cancer Research UK

Keywords: Barrett's oesophagus; HIF-I $\alpha$; HIF-2 $\alpha$; VEGF; hypoxia

Barrett's oesophagus is a pre-malignant condition associated with a 30-125-fold increase in the risk of developing adenocarcinoma compared with unaffected individuals (Guindi and Riddell, 2003). The normal squamous oesophageal lining is transformed via injury caused by gastro-oesophageal reflux disease into columnar-lined epithelium. The subsequent development of specialised intestinal metaplasia (IM) is a key risk factor for tumorigenesis (Spechler and Goyal, 1996). Additional genetic and epigenetic events are associated with further progression through increasingly severe degrees of dysplasia to adenocarcinoma. This process is termed the Barrett's metaplasia-dysplasia-adenocarcinoma sequence (Jankowski et al, 1999). Oesophageal adenocarcinoma is a devastating disease, which is increasing in incidence. In Europe, only about a quarter of all oesophageal cancers are operable and, for these, 5 -year survival is around 20-30\% (Keighley, 2003). Regular endoscopic surveillance is recommended for patients with Barrett's metaplasia because of their elevated risk of developing adenocarcinoma (Bergman and Tytgat, 2005). Cancers detected in such programmes are frequently early stage and have a better prognosis (Streitz et al, 1993; Corley et al, 2002). However, these analyses are subject to confounding factors such as lead and length time bias,

\footnotetext{
*Correspondence: Dr CML West;
}

E-mail: Catharine.West@manchester.ac.uk

Received 29 November 2006; revised 19 March 2007; accepted 20 March 2007; published online 17 April 2007 and it remains to be established conclusively if surveillance is beneficial.

The exact molecular mechanisms of Barrett's adenocarcinoma development remain largely unknown, but there is interest in investigating molecular biomarkers for predicting patient risk of disease progression (Bergman and Tytgat, 2005). The rationale underlying such work is to find approaches for identifying highrisk patients who would be targeted for surveillance endoscopy (Preston and Jankowski, 2006). Although many potential biomarkers have been assessed, none is currently in routine clinical use (McManus et al, 2004).

Hypoxia is implicated in the progression of several malignancies, but is relatively unstudied in the Barrett's carcinogenic sequence. Tumour hypoxia is a key factor driving the development of malignancy, and the master regulatory protein that controls the response of cells to changing oxygen levels is hypoxia-inducible factor-1 (HIF-1). HIF-1 consists of constitutively expressed HIF-1 $\beta$ complexed with one of three subunits (HIF- $1 \alpha$, HIF- $2 \alpha$ or HIF- $3 \alpha$ ). In hypoxia, HIF-1 upregulates genes involved in a variety of cellular processes that include glucose metabolism, erythropoiesis, cell proliferation, angiogenesis and apoptosis. Studies have shown progressively increased HIF-1 $\alpha$ expression in breast (Bos et al, 2001), skin (Costa et al, 2001), gastric (Griffiths et al, 2007) and cervical (Acs et al, 2003) cancer development. Hypoxia-inducible factor $-1 \alpha$ is a key mediator of angiogenesis via activation of vascular endothelial growth factor (VEGF) (Forsythe et al, 1996), 
which is associated with oesophageal carcinogenesis (Couvelard et al, 2000; Auvinen et al, 2002; Lord et al, 2003; Mobius et al, 2003). Hypoxia-inducible erythropoietin (Epo) regulates erythropoiesis by stimulating the growth and differentiation of red blood cell precursors (Yasuda et al, 2003). Erythropoietin and erythropoietin receptor (Epo-R) are expressed in a number of cancers and are involved in breast (Acs et al, 2002), endometrial (Acs et al, 2004), melanoma (Kumar et al, 2005) and prostate (Feldman et al, 2006) tumorigenesis. The following study was established to investigate the hypothesis that hypoxia plays a role in the aetiology of oesophageal cancer. The specific goals of the research were to determine whether the expression of hypoxia-associated proteins increases along the Barrett's carcinogenic sequence and to highlight potential markers of interest for further study as predictors of disease progression in patients with Barrett's dysplasia. Four hypoxia-associated markers were selected that have not been assessed in the Barrett's sequence: HIF- $1 \alpha$, HIF- $2 \alpha$, Epo, Epo-R. Although studied previously, VEGF and Glut-1 were studied also. The widely investigated Ki67 was included as a comparator. The expression of the proteins was assessed using immunohistochemistry in paraffin-embedded material representing the Barrett's metaplasia-dysplasia-adenocarcinoma sequence.

\section{METHODS}

\section{Endoscopic biopsies}

The study was approved by the South Manchester Ethics Committee. Paraffin-embedded endoscopic biopsies of 20 normal squamous epithelium (NSE), 15 columnar-lined oesophagus (CLO), 20 CLO with IM, 17 dysplasia and 20 Barrett's type adenocarcinoma were obtained from the pathology archive of South Manchester University Hospitals NHS Trust. Histopathology and endoscopy reports were reviewed to confirm biopsy location in the oesophagus.

Haematoxylin and eosin slides were reassessed by a consultant upper gastrointestinal pathologist (SAP) to select the most suitable specimens for immunohistochemistry. Biopsy samples were classified using internationally agreed criteria (Ibrahim, 2000; Schlemper et al, 2000; Odze, 2006). NSE was defined as normal squamous epithelium with no evidence of adjacent CLO or IM. Seventeen of the biopsies designated NSE had additional fragments of adjacent normal gastric cardia mucosa (NCM) used as additional controls to explore changes due to metaplastic transformation. CLO was defined as the presence of columnar metaplasia of the lower oesophagus without evidence of IM. CLO with IM was defined as columnar metaplasia of the lower oesophagus associated with specialised IM (characterised by goblet cells). Dysplasia was defined as unequivocal neoplastic epithelium strictly confined within the basement membrane of the gland from which it arises. This was classified as low $(n=10)$ and high $(n=7)$ grade depending on the degree of abnormality present. Adenocarcinoma was defined as invasive malignancy of adenocarcinoma cell type arising from the lower oesophagus in association with CLO.

\section{Immunohistochemistry}

As deterioration can occur in stored sections (Bertheau et al, 1998; Olapade-Olaopa et al, 2001), staining was carried out within 3 months of cutting. Sections $(4 \mu \mathrm{m})$ were dewaxed in xylene and rehydrated using a series of ethanol solutions of increasing dilution.

\section{HIF-1 $\alpha$ immunohistochemistry}

Sections were microwaved for $25 \mathrm{~min}$ in $10 \mathrm{~mm}$ sodium citrate buffer solution ( $\mathrm{pH}$ 6.0) and endogenous peroxidase quenched with $0.03 \%$ hydrogen peroxide in methanol. HIF- $1 \alpha$ was detected using the Tyramide Signal Amplification System (PerkinElmer Life Sciences, NEL 700A001KT Beaconsfield, UK), which is based on streptavidin-biotin-horseradish peroxidase complex formation. Following the blocking step described in the manufacturer's protocol, the primary antibody was applied (Table 1). Biotinylated rabbit anti-mouse (DakoCytomation, E0413, Ely, UK) diluted $1: 400$ was used as the secondary antibody and the sections were incubated for $30 \mathrm{~min}$ at room temperature. Additional blocking precautions were employed at this stage in order to minimise the amplification of nonspecific background (Kim et al, 2003). The antibody was visualised using diaminobenzidine (DakoCytomation, UK) and sections counterstained with haematoxylin, dehydrated and mounted.

\section{HIF-2 $\alpha$, Epo, Epo-R, VEGF, Glut-1 and Ki67 immunohistochemistry}

Antigen retrieval was carried out where necessary by microwaving for $25 \mathrm{~min}$ in either $10 \mathrm{~mm}$ sodium citrate ( $\mathrm{pH} 6.0$ ) or $0.05 \mathrm{M}$ Tris-HCl/1 mM EDTA (pH 8.5 or 9.0) buffer solution (Table 1). After quenching endogenous peroxidase, nonspecific binding was blocked using 10\% casein (Vector Laboratories, SP-5020, Peterborough, UK). The primary antibody was applied and the sections were incubated as described (Table 1). Mouse or rabbit (EnVisionPlus System; DakoCytomation, UK) secondary antibodies were used to detect the antigen using a 30-min incubation at room temperature. Following visualisation with diaminobenzidine, sections were counterstained with haematoxylin, dehydrated and mounted. In each case, substitution of the primary antibody with an identical concentration of immunoglobulins (IgG1; DakoCytomation, UK) from the same species served as a negative control. Positive and negative (or low) tissue controls from gastric, cervical or head and neck cancer with known staining characteristics were used in each batch. Batch-to-batch variation was assessed by choosing two sections showing high and low protein expression and running additional sections from these biopsies with each batch.

Table I Summary of the immunohistochemical methods used, number of biopsies examined and overall percentiles for each immunohistochemical marker studied

\begin{tabular}{|c|c|c|c|c|c|c|c|c|}
\hline Antigen & Isotype & Source & Ref & Conc. $\left(\mu \mathrm{g} / \mathrm{ml}^{-1}\right)$ & Incubation & $\mathbf{p} \mathbf{H}^{\mathbf{a}}$ & $n$ & IHC Score $^{b}$ \\
\hline$H I F-\mid \alpha$ & Mouse |gG| & BD Biosciences & 610958 & 2.5 & $\mathrm{o} / \mathrm{n} 4^{\circ} \mathrm{C}$ & 6.0 & $90^{c}$ & $1.3(0,10)$ \\
\hline $\mathrm{HIF}-2 \alpha$ & Mouse $|g G|$ & Cancer Research UK & El90b & 6 & $\mathrm{o} / \mathrm{n} 4^{\circ} \mathrm{C}$ & 6.0 & $89^{c}$ & $0(0,0.5)$ \\
\hline VEGF & Rabbit polyclonal & Santa Cruz Biotechnology & A-20 & 2 & I h $25^{\circ} \mathrm{C}$ & 8.5 & $89^{c}$ & $80(30,192)$ \\
\hline EPO & Mouse $|g G|$ & R\&D Systems & $9 C 2 \mid \mathrm{DII}$ & 30 & $\mathrm{o} / \mathrm{n} 4^{\circ} \mathrm{C}$ & 6.0 & $88^{c}$ & $7.5(0,125)$ \\
\hline $\mathrm{EPO} / \mathrm{R}$ & Rabbit polyclonal & Santa Cruz Biotechnology & C-20 & 0.4 & $\mathrm{o} / \mathrm{n} 4^{\circ} \mathrm{C}$ & 6.0 & $88^{c}$ & $160(30,270)$ \\
\hline Glut-I & Rabbit polyclonal & Alpha Diagnostics Int & GT I2-A & 10 & I h $37^{\circ} \mathrm{C}$ & $\mathrm{n} / \mathrm{a}$ & $89^{c}$ & $0(0,5)$ \\
\hline Ki-67 & Mouse $|g G|$ & Dako-Cytomation & MIB-I & 0.8 & $\mathrm{o} / \mathrm{n} 4^{\circ} \mathrm{C}$ & 9.0 & $89^{c}$ & $30(15,154)$ \\
\hline
\end{tabular}

$\mathrm{IHC}=$ immunohistochemistry; o/n = overnight; $\mathrm{n} / \mathrm{a}=$ not applicable; conc = concentration. ${ }^{\mathrm{a}}$ Antigen retrieval pH. ${ }^{\mathrm{b}}$ Immunohistochemical score was calculated from percentage $(0-100)$ multiplied by intensity $(0-3)$ of expression for each marker studied - 50 th percentile ( 25 and 75 th percentiles). Insufficient tissue available for scoring in some biopsies. 


\section{Immunohistochemical scoring method}

A score was calculated for each marker (range 0-300) by multiplying intensity (none 0 , weak 1 , moderate 2 , strong 3 ) by percentage of expression (range $0-100$ ). Scoring was performed blind by two independent pathologists (SAP, SMG). Any disagreement was resolved by discussion to obtain a final score.

\section{Statistics}

Spearman's rank non-parametric test was used to calculate interobserver and intermarker correlations. To assess possible differences in expression levels in the carcinogenesis sequence, the rank-sum tests Mann-Whitney (for comparison between two groups) and Kruskal-Wallis (for comparison between all biopsy groups) were applied. The non-parametric Jonckheere-Terpstra (JT) test was also used to identify ordered differences among the biopsy categories in the oesophageal carcinogenesis sequence. With this test, the null hypothesis is that the distribution does not differ across ordered categories. To test marker progression in the Barrett's carcinogenesis sequence, the categories NSE, CLO, IM, Dys and Adeno were used. All statistical tests were two-sided at the 0.05 significance level. As adjusting statistical significance depending on the number of tests performed can create problems (Perneger, 1998), no allowance was made for multiple testing.

\section{RESULTS}

The 92 specimens were from 64 men and 29 women who had a median age of 64 (range 26-87) years. There was insufficient tissue left for scoring of between two and four sections for each marker (Table 1). Interobserver agreement for all the markers studied was highly statistically significantly correlated $(P<0.0001$ for all). The final consensus scores in terms of percentiles for each marker are shown in Table 1 . There were weak, statistically significant correlations between the expression levels of a number of markers: Ki67 expression correlated with that of HIF- $2 \alpha \quad(\rho=0.38$, $P<0.001)$, VEGF $(\rho=0.66, P<0.001)$ and Epo-R $(\rho=0.67$, $P<0.001)$; Glut-1 expression correlated with that of HIF- $1 \alpha$ $(\rho=0.38, \quad P<0.001), \quad$ HIF- $2 \alpha \quad(\rho=0.38, \quad P=0.003)$ and Epo $(\rho=0.62, P<0.001)$; HIF- $2 \alpha$ expression correlated with that of HIF- $1 \alpha(\rho=0.40, P<0.001)$ and VEGF $(\rho=0.30, P=0.004)$; Epo-R expression correlated with that of VEGF $(\rho=0.71, P<0.001)$ and inversely with that of Epo $(\rho=-0.28, P=0.009)$.

\section{Descriptive pathology}

Photomicrographs of the immunohistochemical expression of each marker studied are shown in Figure 1. Hypoxia-inducible factor- $1 \alpha$ staining was predominantly nuclear, and occasional cytoplasmic staining was not scored. Staining was focal and tended to be intense in areas adjacent to inflammation and ulceration. Similarly, HIF- $2 \alpha$ staining was predominantly nuclear and occasional focal cytoplasmic staining was ignored. Hypoxia-inducible factor- $2 \alpha$ was not seen in either CLO or IM, but its expression tended to be high ( $>50 \%$ positive cells) in dysplasia and carcinoma. No particular preferred location of staining was identified.

VEGF was expressed in the cytoplasm. Where squamous epithelium was seen there was staining of the basal layers. In CLO and IM, staining was seen in mucous cells (fovelar-type), on the surface, in all layers of the foveolar pit and in goblet cells. In dysplasia and carcinoma, staining was random with no specific architectural pattern identified.

Erythropoietin expression was granular and cytoplasmic. Staining in CLO and IM was mainly in mucous cells located in the basal region of the cell cytoplasm surrounding the nucleus.
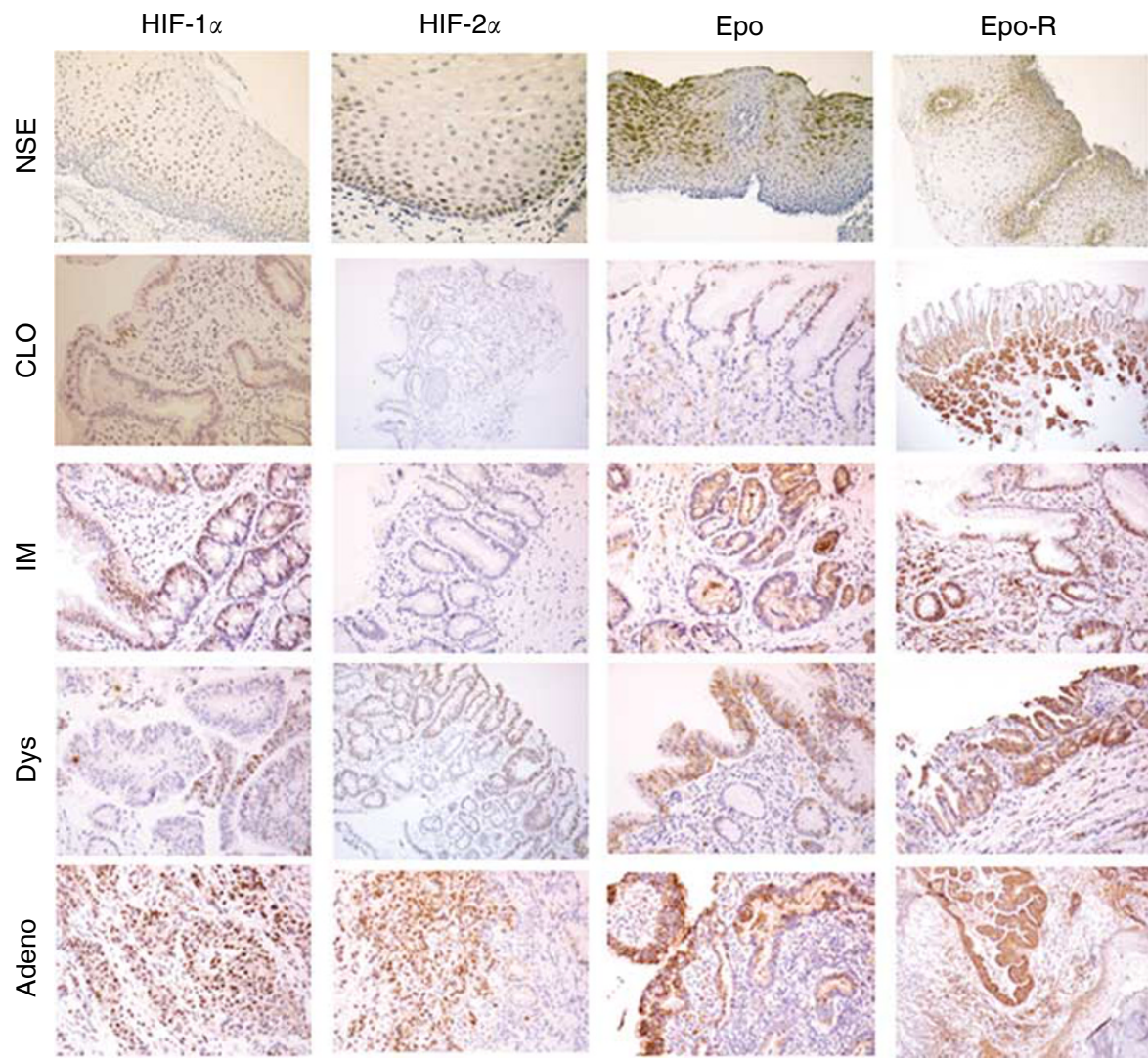

Figure I Representative photomicrographs of HIF-| $\alpha$, HIF-2 $\alpha$, Epo and Epo-R in Barrett's metaplasia-dysplasia-adenocarcinoma sequence. $\mathrm{NSE}=$ normal squamous epithelium; $\mathrm{CLO}=$ columnar-lined oesophagus; IM, intestinal metaplasia; Dys = dysplasia; Adeno = adenocarcinoma. 
Mucous cells in all locations stained (surface and all levels of the foveolar pit) but with a tendency for a higher percentage of surface cells to be positive. Focal staining of chief and parietal cells was also identified. Dysplasia and carcinoma had a random staining pattern. Epo-R staining was cytoplasmic with an increase in intensity around the nucleus. Lymphocytes within the lamina propria were positive for the antibody and acted as an internal control. In CLO and IM, staining was seen in mucous-secreting cells predominantly of the neck region of the foveolar pits. In these cells, the cytoplasmic staining was mainly towards the basal region of the cell around the basally placed nucleus. Staining of goblet cells was also present. In Dys and Adeno, staining was diffuse with a random location of positive cells.

Glut-1 was expressed in lymphocytes within the lamina propria, which acted as an internal control. Staining was cytoplasmic with only a few positive cases detected. No specific location of staining was identified.

Ki67 staining was nuclear. In CLO and IM, mucous cells of the deep and middle third of the foveolar pit showed positive staining with the surface region being negative. Positive staining was also seen in the glands deep to the foveolar pits. In dysplasia and carcinoma, staining was increased and present in all layers of the mucosa with loss of the normal proliferation pattern.

In some biopsies, specialised gastric body mucosa containing chief and parietal cells was present (17 NSE, 8 CLO, 3 IM, 1 dysplasia and 2 adenocarcinoma). The parietal and chief cells all showed strong staining for Epo, Epo-R and VEGF immunohistochemistry, regardless of the morphology of adjacent mucosa. This staining was not observed with HIF- $1 \alpha$, HIF- $2 \alpha$, Glut- 1 and Ki67 staining. It is unclear whether this was secondary to cross-reactivity
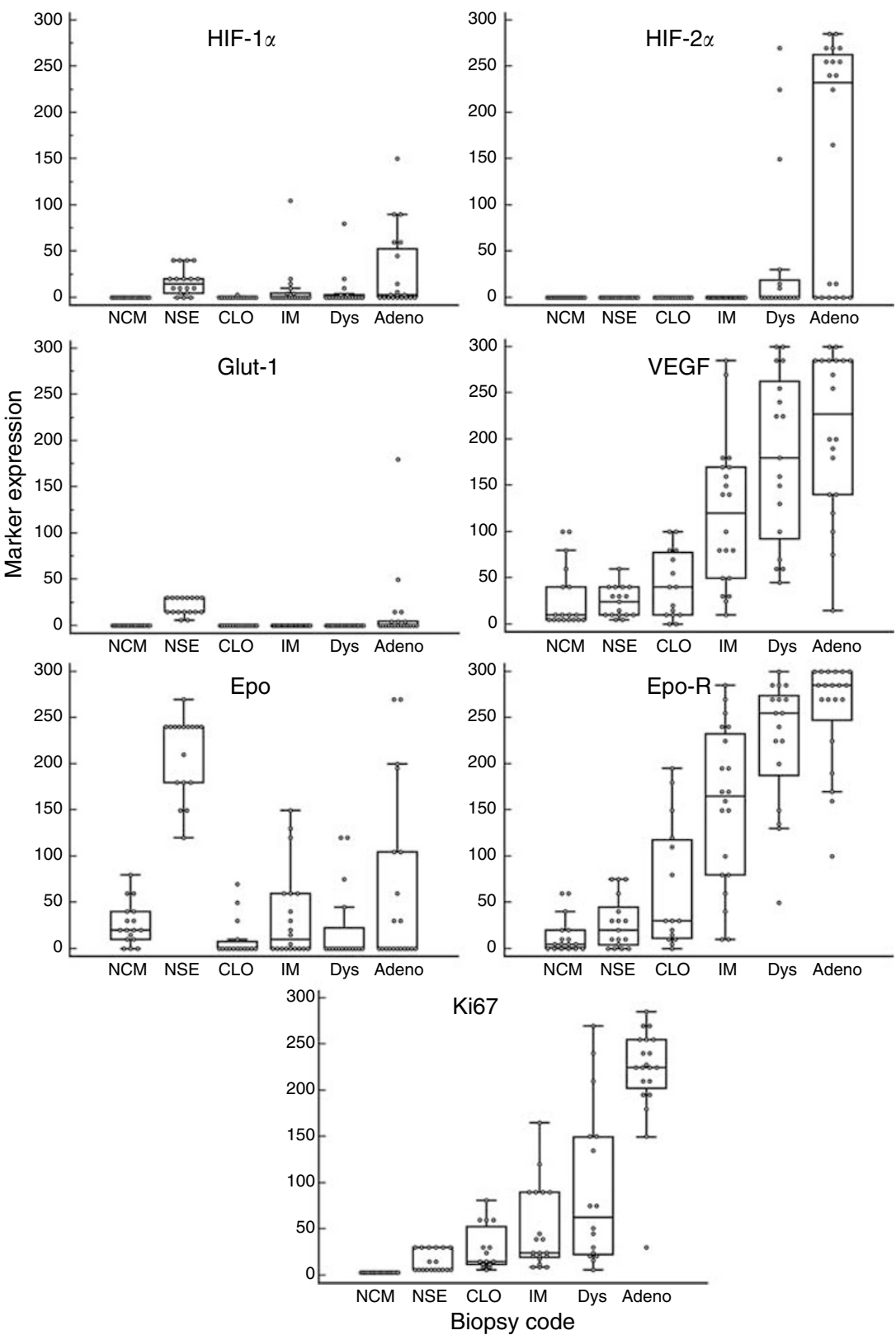

Figure 2 Box and whisker plots of each immunohistochemical marker in the Barrett's sequence. The box represents the 25-75 quartile with a median line. The whiskers extend to minimum and maximum values, but exclude outlying and far out values. Individual data points are also shown. NSE $=$ normal squamous epithelium; $N C M=$ normal gastric cardia mucosa; $\quad C L O=$ columnar-lined oesophagus; $\quad$ M $=$ intestinal metaplasia; $\quad$ Dys=dysplasia; Adeno $=$ adenocarcinoma. 
or true positive staining. Data from these areas were therefore not included in the calculated score for each biopsy.

\section{Marker expression along the Barrett's metaplasia- dysplasia-adenocarcinoma sequence}

Box and whisker plots of marker expression are shown in Figure 2. Using Kruskall-Wallis testing, all markers showed significant differences in expression in the Barrett's metaplasia-dysplasiaadenocarcinoma sequence $(P<0.001$ for all). The JT test assesses ordered differences and showed significant increases in expression for HIF- $2 \alpha(P=0.014)$, VEGF $(P<0.0001)$, Epo-R $(P<0.0001)$ and Ki67 $(P<0.0001)$ from normal squamous tissue to adenocarcinoma. Erythropoietin, Glut- 1 and HIF- $1 \alpha$ showed a decrease in expression from NSE to CLO $(P<0.001$ for all). There were significant differences in marker expression in adenocarcinoma compared with dysplasia for HIF- $1 \alpha(P=0.014)$, HIF- $2 \alpha(P=0.012)$, Ki67 $(P=0.0001)$ and Epo-R $(P=0.042)$.

In some samples of CLO $(n=8)$, IM $(n=10)$, dysplasia $(n=6)$ and adenocarcinoma $(n=16)$, adjacent NSE was available for direct comparison. Increases in the expression of HIF-2 $\alpha$, VEGF, Ki67 and Epo-R in the relevant biopsy category compared with adjacent NSE are shown (Figure 3 ).

\section{DISCUSSION}

Significant increases in the expression of HIF- $2 \alpha$, VEGF, Epo-R and Ki67 $(P<0.0001)$ were found along the Barrett's metaplasia dysplasia-adenocarcinoma sequence. Previous studies have shown the importance of Ki67 expression and proliferation in the progression of Barrett's oesophagus (Iftikhar et al, 1992; Reid

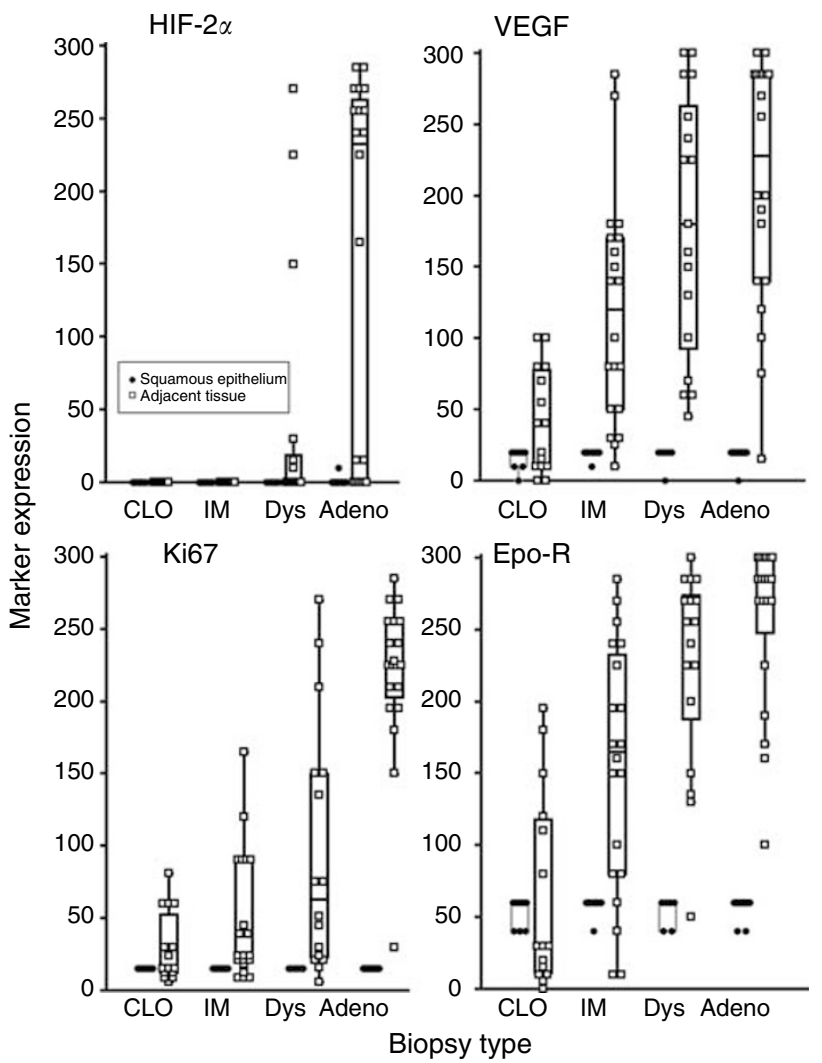

Figure 3 Comparison of the expression of HIF-2 $\alpha$, VEGF, Ki67 and Epo-R in normal squamous epithelium compared with adjacent columnarlined oesophagus (CLO), intestinal metaplasia (IM), dysplasia (Dys) and adenocarcinoma (Adeno). A total of 40 biopsies were studied. et al, 1993; Polkowski et al, 1995; Feith et al, 2004). Similarly, the role of VEGF and angiogenesis in the Barrett's sequence has been widely reported and discussed (Couvelard et al, 2000; Auvinen et al, 2002; Lord et al, 2003; Mobius et al, 2003).

Our finding that Glut-1 is expressed in adenocarcinoma but not in dysplasia agrees with published work (Younes et al, 1997, 2000). These papers reported higher (45-69\%) expression of Glut-1 in Barrett's adenocarcinoma than the $25 \%$ found here. As there was no expression in high-grade dysplasia, the authors concluded that 'Glut-1 immunostaining may provide a unique marker that could distinguish between high grade dysplasia and a well-differentiated carcinoma, when such distinction cannot be made on purely morphological grounds' (Younes et al, 1997). Our confirmatory observation adds weight to this conclusion. We also found a low percentage of Glut-1 staining in the basal layers of normal squamous oesophageal tissue, which has not previously been reported by others.

HIF- $1 \alpha$ expression decreased from NSE to CLO and then increased with progression to adenocarcinoma. Although HIF- $1 \alpha$ is of interest as a marker of hypoxia, its increase in expression from CLO to adenocarcinoma might be inflammatory mediated. Chronic inflammation and reactive oxygen species (ROS)-induced DNA damage are important in oesophageal tumour carcinogenesis (Olyaee et al, 1995; Jimenez et al, 2005). Reactive oxygen species regulate HIF stability and transcriptional activity under hypoxia and normoxia (Pouyssegur and Mechta-Grigoriou, 2006). Inflammation-mediated COX-2 expression is an early feature of Barrett's carcinogenesis (Morris et al, 2001) and, in a gastric cancer model, the COX-2/PGE2/HIF-1/VEGF pathway was shown to contribute to tumour angiogenesis (Huang et al, 2005).

As ROS are also involved in the stabilisation of HIF- $2 \alpha$ (Guzy et al, 2005), ROS due to chronic inflammation might also play a role in the increasing expression of HIF-2 in the Barrett's sequence. The high expression of HIF- $2 \alpha$ in dysplasia and adenocarcinoma makes it of interest for further investigation in a case-control study as a potential predictor of progression to malignancy in patients with dysplasia. It might have a future role in differentiating nonspecific (reactive) features that can mimic dysplasia from true dysplasia or early well-differentiated adenocarcinoma.

Epo was expressed in normal squamous oesophageal tissue and there was no increase in expression along the progression sequence. Erythropoietin receptor, however, was expressed more abundantly and staining increased from normal squamous tissue to invasive oesophageal cancer. Of interest, both were expressed earlier in the Barrett's sequence than either HIF- $1 \alpha$ or HIF- $2 \alpha$. Non-hypoxia stimulation of Epo/Epo-R involves a variety of factors, including various hormones and cytokines (Hardee et al, 2006). In addition to regulation of red blood cell production, the pleiotropic effects of Epo/Epo-R signalling include stimulation of proliferation and angiogenesis (Hardee et al, 2006). Erythropoietin has been shown to act in the protection of tissue from injury and can decrease inflammation (Grasso et al, 2004). The early expression of Epo and its receptor in the Barrett's sequence is probably, therefore, related to their role in protection from inflammation rather than hypoxia response.

There was a reasonably high correlation between the scores of many of the immunohistochemical markers studied. This is probably a reflection of the biological similarity of the proteins studied in terms of their response to inflammation and involvement in the stimulation of angiogenesis and proliferation.

There is interest in using molecular markers to identify patients with a high risk of developing adenocarcinoma in whom surveillance endoscopy can be targeted. It is probably unlikely that a single marker will be sufficient, as there appears to be no simple evolution of genetic or molecular alterations in disease progression (Jenkins et al, 2002). Rather there appears to be a heterogeneous accumulation of genetic and molecular changes in the Barrett's metaplasia-dysplasia-adenocarcinoma sequence 
(Jenkins et al, 2002). As the molecular changes are known to be extremely complex, this is impeding further research. In addition, this heterogeneity may ultimately be responsible for the poor response of these tumours to therapy. Given the multiple genetic alterations, which are implicated in the natural history of oesophageal adenocarcinoma, a combination of clinical risk factors and carefully validated biomarkers might improve further the predictive value of the molecular approach (Bani-Hani et al, 2000; Bani-Hani et al, 2005) and allow targeted surveillance.

HIF-2 $\alpha$, VEGF, Epo-R and Ki67 showed increased expression with progression along the Barrett's carcinogenesis sequence. The late expression of HIF- $1 \alpha$ and HIF- $2 \alpha$, key mediators of gene induction in response to hypoxia, suggests that hypoxia might not be a key factor driving oesophageal cancer development. As discussed above, ROS and inflammation are likely to be involved in the stimulation of many of the proteins studied. The conclusion from this work, therefore, is that hypoxia is probably not important in the aetiology of oesophageal cancer. The late expression of HIF- $2 \alpha$ in the Barrett's sequence and its high expression in adenocarcinoma suggest that it is worth further investigation as a marker of disease progression and therapeutic target.

\section{ACKNOWLEDGEMENTS}

We thank David Ryder, Department of Statistics, Christie Hospital for help with the statistical analysis and Dr Jo Cresswell, Academic Radiation Oncology, Christie Hospital, Manchester for administrative support. This work was supported by Cancer Research UK and the National Translational Research Network of the UK.

\section{REFERENCES}

Acs G, Xu X, Chu C, Acs P, Verma A (2004) Prognostic significance of erythropoietin expression in human endometrial carcinoma. Cancer 100: $2376-2386$

Acs G, Zhang PJ, McGrath CM, Acs P, McBroom J, Mohyeldin A, Liu S, Lu $\mathrm{H}$, Verma A (2003) Hypoxia-inducible erythropoietin signaling in squamous dysplasia and squamous cell carcinoma of the uterine cervix and its potential role in cervical carcinogenesis and tumor progression. Am J Pathol 162: $1789-1806$

Acs G, Zhang PJ, Rebbeck TR, Acs P, Verma A (2002) Immunohistochemical expression of erythropoietin and erythropoietin receptor in breast carcinoma. Cancer 95: 969-981

Auvinen MI, Sihvo EI, Ruohtula T, Salminen JT, Koivistoinen A, Siivola P, Ronnholm R, Ramo JO, Bergman M, Salo JA (2002) Incipient angiogenesis in Barrett's epithelium and lymphangiogenesis in Barrett's adenocarcinoma. J Clin Oncol 20: $2971-2979$

Bani-Hani K, Martin IG, Hardie LJ, Mapstone N, Briggs JA, Forman D, Wild CP (2000) Prospective study of cyclin D1 overexpression in Barrett's esophagus: association with increased risk of adenocarcinoma. J Natl Cancer Inst 92: 1316-1321

Bani-Hani KE, Bani-Hani BK, Martin IG (2005) Characteristics of patients with columnar-lined Barrett's esophagus and risk factors for progression to esophageal adenocarcinoma. World J Gastroenterol 11: 6807-6814

Bergman JJ, Tytgat GN (2005) New developments in the endoscopic surveillance of Barrett's oesophagus. Gut 54(Suppl 1): i38-i42

Bertheau P, Cazals-Hatem D, Meignin V, de Roquancourt A, Verola O, Lesourd A, Sene C, Brocheriou C, Janin A (1998) Variability of immunohistochemical reactivity on stored paraffin slides. J Clin Pathol 51: 370-374

Bos R, Zhong H, Hanrahan CF, Mommers EC, Semenza GL, Pinedo HM, Abeloff MD, Simons JW, van Diest PJ, van der Wall E (2001) Levels of hypoxia-inducible factor-1 alpha during breast carcinogenesis. J Natl Cancer Inst 93: 309-314

Corley DA, Levin TR, Habel LA, Weiss NS, Buffler PA (2002) Surveillance and survival in Barrett's adenocarcinomas: a population-based study. Gastroenterology 122: 633-640

Costa A, Coradini D, Carrassi A, Erdas R, Sardella A, Daidone MG (2001) Re: Levels of hypoxia-inducible factor-1alpha during breast carcinogenesis. J Natl Cancer Inst 93: 1175-1177

Couvelard A, Paraf F, Gratio V, Scoazec JY, Henin D, Degott C, Flejou JF (2000) Angiogenesis in the neoplastic sequence of Barrett's oesophagus. Correlation with VEGF expression. J Pathol 192: 14-18

Feith M, Stein HJ, Mueller J, Siewert JR (2004) Malignant degeneration of Barrett's esophagus: the role of the Ki-67 proliferation fraction, expression of E-cadherin and p53. Dis Esophagus 17: 322-327

Feldman L, Wang Y, Rhim JS, Bhattacharya N, Loda M, Sytkowski AJ (2006) Erythropoietin stimulates growth and STAT5 phosphorylation in human prostate epithelial and prostate cancer cells. Prostate 66: $135-145$

Forsythe JA, Jiang BH, Iyer NV, Agani F, Leung SW, Koos RD, Semenza GL (1996) Activation of vascular endothelial growth factor gene transcription by hypoxia-inducible factor 1. Mol Cell Biol 16: 4604-4613

Grasso G, Sfacteria A, Cerami A, Brines M (2004) Erythropoietin as a tissueprotective cytokine in brain injury: what do we know and where do we go? Neuroscientist 10: $93-98$
Griffiths EA, Pritchard SA, Valentine HR, Whitchelo N, Bishop PW, Ebert MP, Price PM, Welch IM, West CM (2007) Hypoxia-inducible factorlalpha expression in the gastric carcinogenesis sequence and its prognostic role in gastric and gastro-oesophageal adenocarcinomas. Br J Cancer 96: 95 - 103

Guindi M, Riddell RH (2003) Histology of Barrett's esophagus and dysplasia. Gastrointest Endosc Clin N Am 13: 349-368, , viii

Guzy RD, Hoyos B, Robin E, Chen H, Liu L, Mansfield KD, Simon MC, Hammerling U, Schumacker PT (2005) Mitochondrial complex III is required for hypoxia-induced ROS production and cellular oxygen sensing. Cell Metab 1: $401-408$

Hardee ME, Arcasoy MO, Blackwell KL, Kirkpatrick JP, Dewhirst MW (2006) Erythropoietin biology in cancer. Clin Cancer Res 12: $332-339$

Huang SP, Wu MS, Shun CT, Wang HP, Hsieh CY, Kuo ML, Lin JT (2005) Cyclooxygenase-2 increases hypoxia-inducible factor-1 and vascular endothelial growth factor to promote angiogenesis in gastric carcinoma. J Biomed Sci 12: 229-241

Ibrahim NB (2000) ACP. Best Practice No 155. Guidelines for handling oesophageal biopsies and resection specimens and their reporting. J Clin Pathol 53: 89-94

Iftikhar SY, Steele RJ, Watson S, James PD, Dilks K, Hardcastle JD (1992) Assessment of proliferation of squamous, Barrett's and gastric mucosa in patients with columnar lined Barrett's oesophagus. Gut 33: $733-737$

Jankowski JA, Wright NA, Meltzer SJ, Triadafilopoulos G, Geboes K, Casson AG, Kerr D, Young LS (1999) Molecular evolution of the metaplasia-dysplasia-adenocarcinoma sequence in the esophagus. Am J Pathol 154: $965-973$

Jenkins GJ, Doak SH, Parry JM, D’Souza FR, Griffiths AP, Baxter JN (2002) Genetic pathways involved in the progression of Barrett's metaplasia to adenocarcinoma. Br J Surg 89: 824-837

Jimenez P, Piazuelo E, Sanchez MT, Ortego J, Soteras F, Lanas A (2005) Free radicals and antioxidant systems in reflux esophagitis and Barrett's esophagus. World J Gastroenterol 11: $2697-2703$

Keighley MR (2003) Gastrointestinal cancers in Europe. Aliment Pharmacol Ther 18(Suppl 3): 7-30

Kim SH, Shin YK, Lee KM, Lee JS, Yun JH, Lee SM (2003) An improved protocol of biotinylated tyramine-based immunohistochemistry minimizing nonspecific background staining. J Histochem Cytochem 51: $129-132$

Kumar SM, Acs G, Fang D, Herlyn M, Elder DE, Xu X (2005) Functional erythropoietin autocrine loop in melanoma. Am J Pathol 166: $823-830$

Lord RV, Park JM, Wickramasinghe K, DeMeester SR, Oberg S, Salonga D, Singer J, Peters JH, Danenberg KD, Demeester TR, Danenberg PV (2003) Vascular endothelial growth factor and basic fibroblast growth factor expression in esophageal adenocarcinoma and Barrett esophagus. J Thorac Cardiovasc Surg 125: 246-253

McManus DT, Olaru A, Meltzer SJ (2004) Biomarkers of esophageal adenocarcinoma and Barrett's esophagus. Cancer Res 64: 1561-1569

Mobius C, Stein HJ, Becker I, Feith M, Theisen J, Gais P, Jutting U, Siewert JR (2003) The 'angiogenic switch' in the progression from Barrett's metaplasia to esophageal adenocarcinoma. Eur J Surg Oncol 29: 890 - 894 
Morris CD, Armstrong GR, Bigley G, Green H, Attwood SE (2001) Cyclooxygenase-2 expression in the Barrett's metaplasia-dysplasiaadenocarcinoma sequence. Am J Gastroenterol 96: 990 -996

Odze RD (2006) Diagnosis and grading of dysplasia in Barrett's oesophagus. J Clin Pathol 59: $1029-1038$

Olapade-Olaopa EO, Ogunbiyi JO, MacKay EH, Muronda CA, Alonge TO, Danso AP, Moscatello DK, Sandhu DP, Shittu OB, Terry TR, Wong AJ, Habib FK (2001) Further characterization of storage-related alterations in immunoreactivity of archival tissue sections and its implications for collaborative multicenter immunohistochemical studies. Appl Immunohistochem Mol Morphol 9: 261-266

Olyaee M, Sontag S, Salman W, Schnell T, Mobarhan S, Eiznhamer D, Keshavarzian A (1995) Mucosal reactive oxygen species production in oesophagitis and Barrett's oesophagus. Gut 37: 168-173

Perneger TV (1998) What's wrong with Bonferroni adjustments. BMJ 316: $1236-1238$

Polkowski W, van Lanschot JJ, Ten Kate FJ, Baak JP, Tytgat GN, Obertop H, Voorn WJ, Offerhaus GJ (1995) The value of p53 and Ki67 as markers for tumour progression in the Barrett's dysplasia-carcinoma sequence. Surg Oncol 4: $163-171$

Pouyssegur J, Mechta-Grigoriou F (2006) Redox regulation of the hypoxiainducible factor. Biol Chem 387: $1337-1346$

Preston SL, Jankowski JA (2006) Drinking from the fountain of promise: biomarkers in the surveillance of Barrett's oesophagus - the glass is half full!. Gut 55: $1377-1379$

Reid BJ, Sanchez CA, Blount PL, Levine DS (1993) Barrett's esophagus: cell cycle abnormalities in advancing stages of neoplastic progression. Gastroenterology 105: 119-129
Schlemper RJ, Riddell RH, Kato Y, Borchard F, Cooper HS, Dawsey SM, Dixon MF, Fenoglio-Preiser CM, Flejou JF, Geboes K, Hattori T, Hirota T, Itabashi M, Iwafuchi M, Iwashita A, Kim YI, Kirchner T, Klimpfinger $M$, Koike $M$, Lauwers GY, Lewin KJ, Oberhuber G, Offner F, Price AB, Rubio CA, Shimizu M, Shimoda T, Sipponen P, Solcia E, Stolte M, Watanabe H, Yamabe H (2000) The Vienna classification of gastrointestinal epithelial neoplasia. Gut 47: $251-255$

Spechler SJ, Goyal RK (1996) The columnar-lined esophagus, intestinal metaplasia, and Norman Barrett. Gastroenterology 110: $614-621$

Streitz Jr JM, Andrews Jr CW, Ellis Jr FH (1993) Endoscopic surveillance of Barrett's esophagus. Does it help? J Thorac Cardiovasc Surg 105: 383 - 387; discussion 387-388

Yasuda Y, Fujita Y, Matsuo T, Koinuma S, Hara S, Tazaki A, Onozaki M, Hashimoto M, Musha T, Ogawa K, Fujita H, Nakamura Y, Shiozaki H, Utsumi H (2003) Erythropoietin regulates tumour growth of human malignancies. Carcinogenesis 24: $1021-1029$

Younes M, Ertan A, Lechago LV, Somoano J, Lechago J (1997) Human erythrocyte glucose transporter (Glut1) is immunohistochemically detected as a late event during malignant progression in Barrett's metaplasia. Cancer Epidemiol Biomarkers Prev 6: 303-305

Younes M, Lechago J, Chakraborty S, Ostrowski M, Bridges M, Meriano F, Solcher D, Barroso A, Whitman D, Schwartz J, Johnson C, Schmulen AC, Verm R, Balsaver A, Carlson N, Ertant A (2000) Relationship between dysplasia, p53 protein accumulation, DNA ploidy, and Glut1 overexpression in Barrett metaplasia. Scand J Gastroenterol 35: $131-137$ 